TP Periodica Polytechnica

Transportation Engineering

42(2), pp. 139-143, 2014

DOI:10.3311/PPtr.7429

Creative Commons Attribution (i)

RESEARCH ARTICLE

\section{Analysis of Dependence of Internal Friction on Temperature of Magnesium Alloy with Aluminium Addition}

Andrea Soviarová / Peter Palček / Dalibor Blažek / Maria Chalupová

RECEIVED 13 MARCH 2014

\begin{abstract}
Internal friction is reflecting a conversion of mechanical energy to heat and causes attenuation of vibrations in the material. This article is aimed at the effect of precipitation hardening on the hardness of AZ 61 magnesium alloy. The changes of microstructure were mapped by internal friction with use of the ultrasonic resonance device. The goal was to find the relationship between the internal friction and microstructure of the experimental material.
\end{abstract}

\section{Keywords \\ Internal friction $\cdot \mathrm{Mg}$-Al alloy $\cdot$ precipitation}

\section{Andrea Soviarová}

Department of Material Engineering, Faculty of Mechanical Engineering, University of Žilina, Univerzitná 8215/1, 01026 Žilina, Slovakia e-mail: andrea.soviarova@fstroj.uniza.sk

\section{Peter Palček}

Department of Material Engineering, Faculty of Mechanical Engineering, University of Žilina, Univerzitná 8215/1, 01026 Žilina, Slovakia e-mail: peter.palcek@,fstroj.uniza.sk

\section{Dalibor Blažek}

VŠB - Technical University of Ostrava, Nanotechnology Centre, 17. listopadu 15, 70833 Ostrava-Poruba, Czech Republic e-mail:dblazek@gmail.com

\section{Mária Chalupová}

Department of Material Engineering, Faculty of Mechanical Engineering, University of Žilina, Univerzitná 8215/1, 01026 Žilina, Slovakia e-mail: maria.chalupova@fstroj.uniza.sk

\section{Introduction}

Nowadays we are challenging a large demand for an effective use of materials based on magnesium. Due to its specific weight, corrosion resistance, density and strength, magnesium alloys are very interesting materials for applications in different industries. (Avedesian, 1999; Markovits and Bauernhuber, 2014)

Damping capacity of alloys is closely tied to the presence of defects including solute atoms, second phases and dislocations (Horvath et. al., 2012a). The interaction between moving dislocations and point defects is one of the major internal friction mechanisms (Horvath et. al., 2012b; Horvath et. al. 2012c) in magnesium alloys so the precipitates influence the damping capacity and contributes to friction properties. Pure magnesium has a very high friction capacity at room temperature due to the easy movement of dislocations. (Sugimoto, 1975; Riehemann, 1998)

However, the increase in the concentration of soluted atoms like $\mathrm{Al}, \mathrm{Ca}$ and $\mathrm{Zn}$, impurities and precipitates are restricting dislocation mobility might lead to reductions in the friction capacity of Mg alloys. (Weltsch et. al., 2013; Markovits et. al., 2013)

With suitable alloying the mechanical properties of magnesium can be improved without compromising its density advantage. Commercial alloys as AZ61 may be used for both, casting and wrought applications, although today most magnesium alloys are used for casting, but magnesium alloy AZ 61 is the most widely used for wrought. (Göken, 2005)

From an engineering point of view there is a demand for alloys with high friction capacity and good mechanical properties for use in vibration-resistant structures.

\section{Experimental procedure}

The material used for experimental study was magnesium alloy AZ61 (Al5.48wt\% Zn0.81 wt\% Mn0.40 wt\% Ca0.32 wt $\%$ ). It was manufactured by squeeze casting method. The microstructure of the magnesium alloy was evaluated in the as-cast and annealed state. The original microstructure after squeeze casting was dendritic. In the interdendritic areas, there 


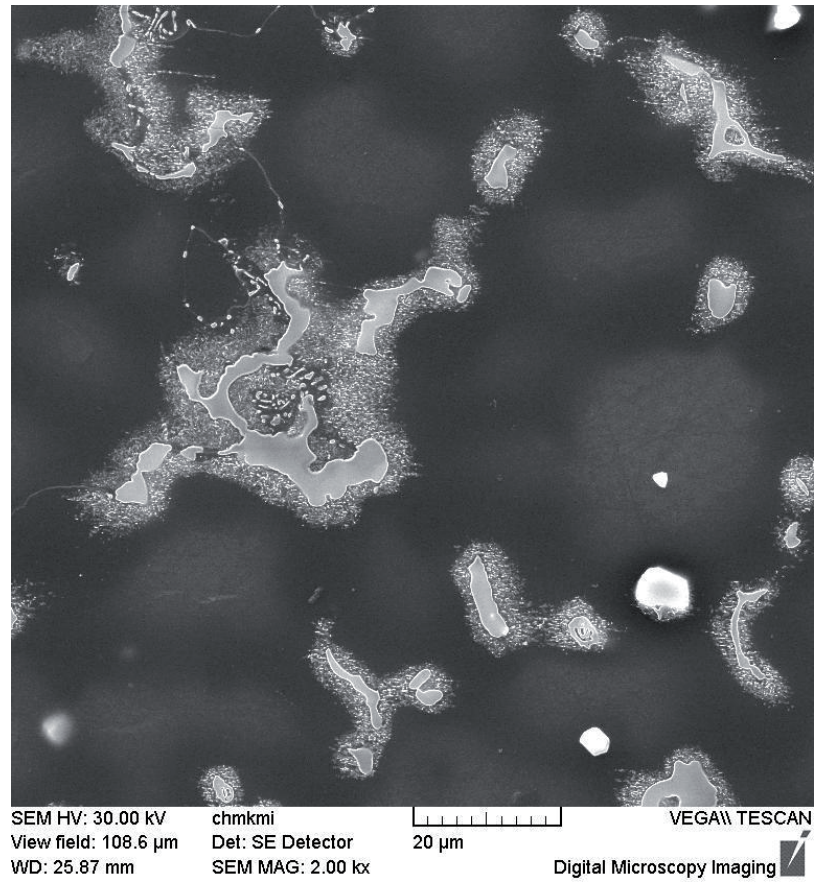

Fig. 1. Mictrustructure as-cast (SEM)

were present many intermetallic phases, (Fig. 1). The most important was $\mathrm{Mg}_{17} \mathrm{Al}_{12}$ intermetallic phase.

After heat treatment for 22 hours at $420^{\circ} \mathrm{C}$ almost all phases in the interdendritic areas were dissoluted and material was homogenized. The microstructure after annealing consists of the polyedric grains with clearly visible grain boundaries, (Fig. 2).

The experimental equipment based on the resonance method consists of the measuring and control part, heating and ultrasonic part. (Blažek and Palček, 2012; Porubčan, 2012; Soviarová et. al., 2013a) Ultrasound generator creates a sine wave. The electric signal is amplified and subsequently transformed into mechanical wave by the piezoceramic transducer.

The ultrasonic wave is concentrated in aluminium horn and spreads to the specimen through a titanium rod. After passing through the specimen the wave is reflected at the free end and spreads back through the entire apparatus until it again reflected at the free end of a steel mirror, which is under the transducer. The amplitude of mechanical wave is decreasing during the propagation due to the internal friction of material. After second reflection the mechanical wave interfere with itself. The standing wave is set up in the apparatus. The amplitude of resulting oscillations is measured by an amperemeter as the current in piezoceramics transducer is proportional to the strain rate. (Blažek, 2012)

The geometry of used experimental equipment is optimalised for the measurements at the resonant frequency $f_{r}$ about $20.5 \mathrm{kHz}$, but this is just one of many resonant frequencies which can be used by this equipment. The mass of ultrasonic resonance equipment (Fig. 3), used at Department of Materials Engineering, University of Žilina.

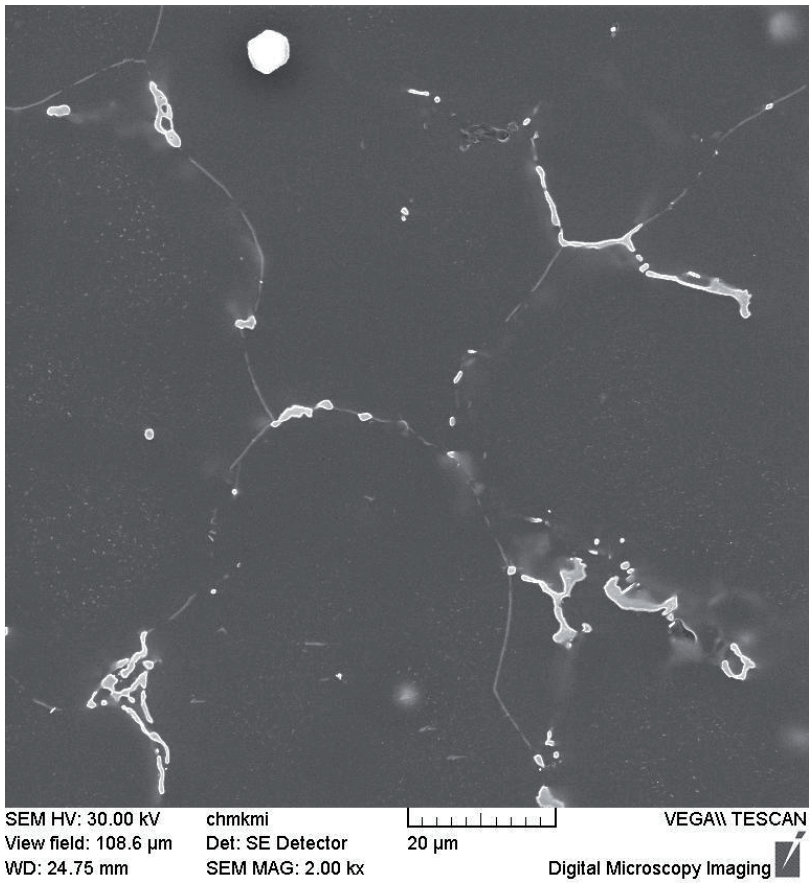

Fig. 2. Microstructure after heat treatment $22 \mathrm{~h} / 420{ }^{\circ} \mathrm{C}$ (SEM)

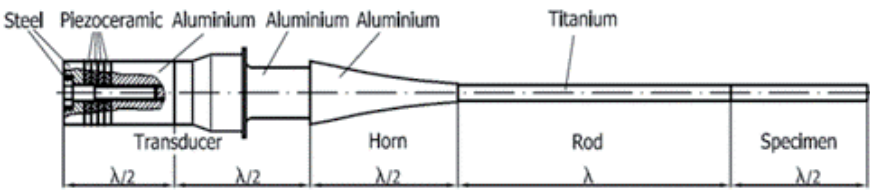

Fig. 3. Mechanical part of experimental equipment

The internal friction of the material is expressed by the loss factor

$$
\eta=\frac{1}{2 \pi} \frac{\Delta \mathrm{w}}{\mathrm{w}}
$$

where $\Delta W$ is a mechanical energy dissipated per one cycle and $W$ is a mechanical energy accumulated in material. The imaginary part of Young modulus E" contains the information about the amount of energy, which is lost in one period

$$
\Delta W=\varepsilon \pi_{0}^{2} E^{\prime \prime}
$$

and the real part of modulus contains the information about the amount of deformation energy $\mathrm{W}$, which is accumulated in the material

$$
W=0,5 E^{\prime} \varepsilon_{0}^{2}
$$

where $\varepsilon_{0}$ is a the strain amplitude of vibrations.

Because the amplitude of oscillations depends on the frequency of the loading signal, the resonant peak can be measured. The information about internal friction of the material of specimen is obtained from the quality factor $Q$ of the whole resonant system. The method of the width of the resonance peak on the $3 \mathrm{~dB}$ level was used and the quality factor is 


$$
Q^{-1}=\frac{f_{2}-f_{1}}{f_{r}}
$$

Measuring of the resonance quality $\mathrm{Q}^{-1}$ takes much longer time then using for example sub-resonance method or the oscillation method, but the results are more accurate, without the need of device calibration (Blažek, 2011). The hardness of material was measured in addition. The test specimens for evaluation of the dependence of hardness on the aging time had a shape of a cube with edge of $15 \mathrm{~mm}$. The Vickers hardness method HV0.5 was used for experimental measurements which were carried out on Zwick / Roell Indentec ZH $\mu$ hardness tester.

The precipitation hardening was carried out at an aging temperature of $200^{\circ} \mathrm{C}$ at predetermined time intervals. The average hardness of the annealed material was $60 \mathrm{HV}$. From the obtained hardness values it is clear, that the hardness of the alloy AZ61 was not increasing with increasing time of precipitation hardening, (Fig. 4). During the aging up to $120 \mathrm{~min}$. the hardness didn't significantly changed. (Soviarová et. al., 2013b)

\section{Result and discussion}

Ultrasonic resonance system can measure the internal friction at a single frequency only. It is necessary to adjust the specimen resonant frequency before the measurement so the resonance frequency of ultrasonic horn with mounted specimen is the same as resonance frequency of the ultrasonic horn itself.

The specimens machined from the squeeze casted AZ61 without any heat treatments were used for measurement.

It can be seen, that our measured waveforms can be divided into two periods (Fig. 5). First interval of temperatures from room temperature up to $150^{\circ} \mathrm{C}$ and the second temperature interval from $150^{\circ} \mathrm{C}$ to $350^{\circ} \mathrm{C}$ (the end of the measurement). Some local maxima of internal friction appear in first temperature interval. Similar behavior was found in previous work

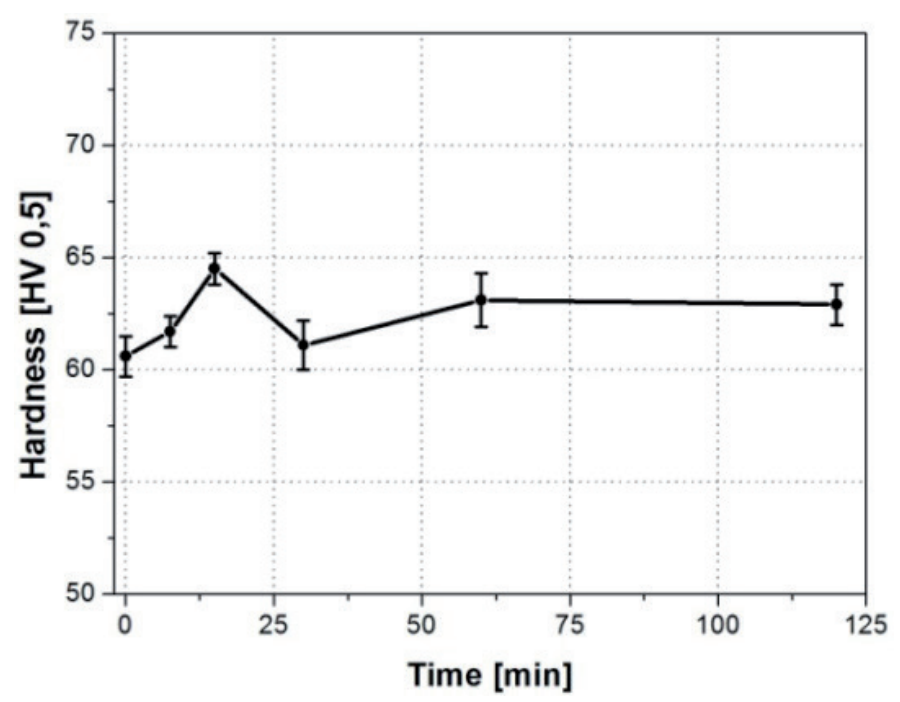

Fig. 4. Dependence of hardness on aging time
(Kasenčák, 2010; Horvath et. al., 2012d). The origin of these maxima is still not clear and there is still a discussion about the reason of their creation. According to previous studies (Kasenčák, 2010; Námešný, 2008) the presence of these small peaks depends on many factors and have a little to do with studied material properties. Apart from minor differences of the three measured waveforms it can be said, that internal friction in the first interval is constant and it is not affected by the microstructural changes of the material.

Significant changes have occurred in the upper temperature interval. Generally speaking, the internal friction grows with rising temperature in this interval. While the friction grows monotonically during the first measurements, significant deviations occurred in the next measurements. In the second measurement the friction followed the previous behavior up to the temperature of $230^{\circ} \mathrm{C}$, where a short plateau appeared prior to the further increase. During the third measurement a small decrease of the internal friction was obtained above the temperature $150^{\circ} \mathrm{C}$, prior to much more pronounced plateau. The further increase of internal friction continued behind the temperature of $225^{\circ} \mathrm{C}$. The increase of internal friction at higher temperature is explained by various mechanisms, mostly by the dislocation motion and slippage at the grain boundaries. The dissolution of intermetallic phases and rising mobility of impurity atoms are important factors which strongly affect the mentioned mechanisms and affect the resulting internal friction.

After completing the internal friction measurements a cross cut from the used test specimen was made with aim to evaluate changes in the microstructure. It was found that repeated heating of the specimen from room temperature to $350^{\circ} \mathrm{C}$ for three times did not significantly changed the microstructure (Fig 6). Anyway some changes are noticeable. The ongoing material homogenization is apparent. The dissolving intermetallic particles are surrounded by wider strip of discontinuous precipitate,

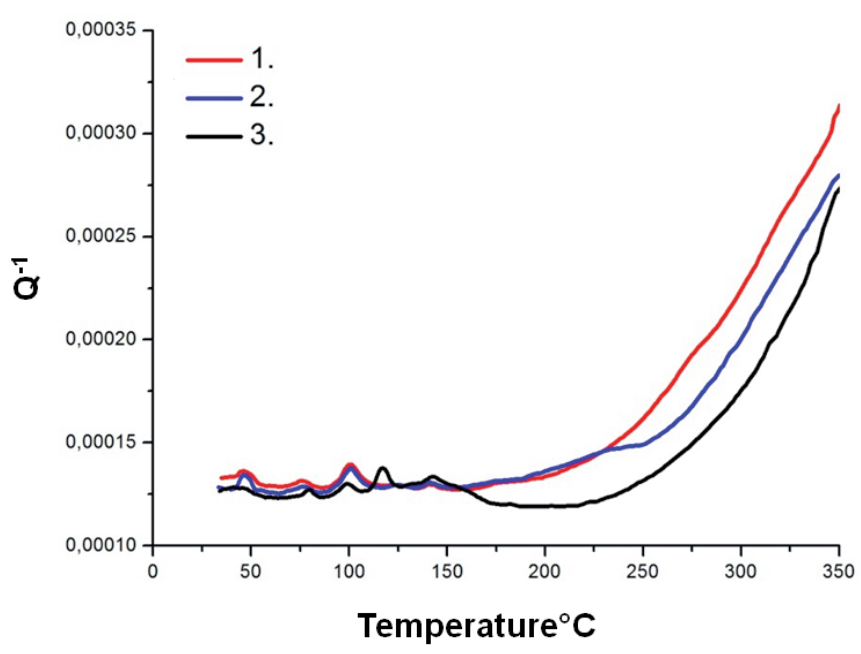

Fig. 5. Temperature depence on internal damping 


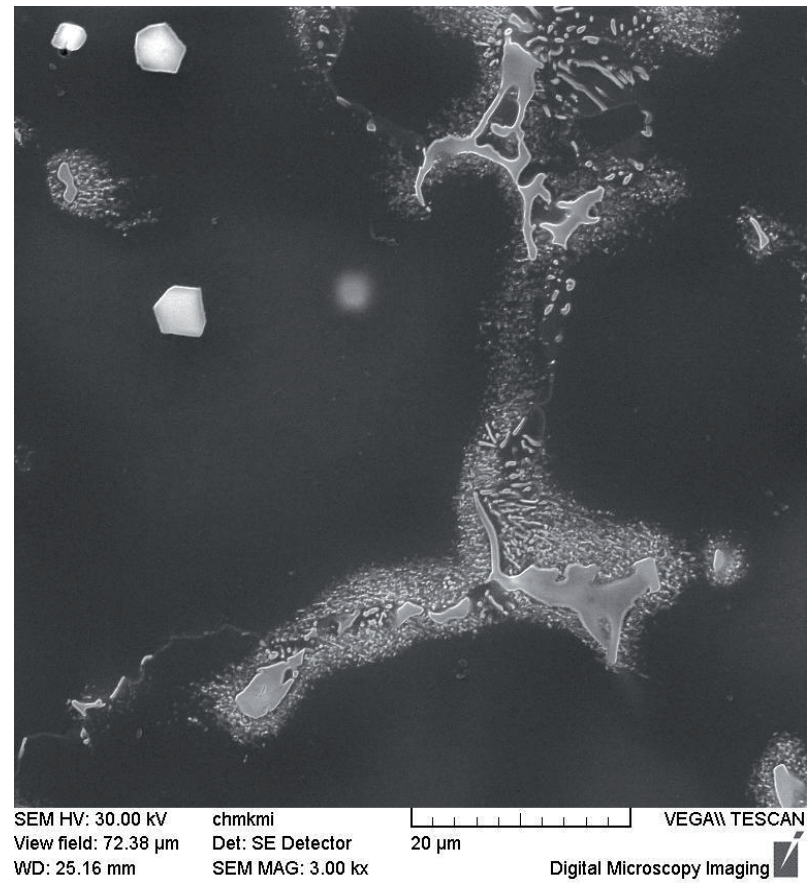

Fig. 6. Microstructure after the three measurements of internal friction

which consist of larger particles compared to the Fig. 1. The appearance of the precipitate is obviously affected by the slow cooling of the specimen in the furnace after the measurement, and the precipitate has enough time for growth.

\section{Conclusion}

Based on experimental results from heat treatment and internal damping measurement of AZ61 magnesium alloy can be stated:

- precipitation of intermetallic phases does not increase the material hardness,

- not all intermetallic phases are dissoluted during homogenization annealing,

- the internal friction increases with increasing of temperature (temperature range from $25^{\circ} \mathrm{C}$ to $350^{\circ} \mathrm{C}$ ),

- relative decreasing of internal friction at elevated temperatures was probably caused by homogenization of the material, dissolving of large intermetallic particles in the interdendritic areas and precipitation during cooling microstructure of the material significantly influences the dependence of internal friction on the temperature making the measurement of internal friction applicable to the evaluation of the microstructure state of material,

- microstructure after three temperature dependent measurements of the internal friction up to the temperature $350^{\circ} \mathrm{C}$ was subtle changes.

\section{Acknowledgements}

This work has been supported by Scientific Grant Agency of Ministry of Education of Slovak republic and Slovak Academy of Sciences No1/0797/12 and project SK-PL-0083-12.

This work was supported by IT4Innovations Centre of Excellence project (CZ.1.05/1.1.00/02.0070), by "New creative teams in priorities of scientific research" (CZ.1.07/2.3.00/30.0055) and the Grant Agency of the Czech Republic (No. P205/11/2137).

\section{References}

Avedesian M. and Baker H. (1999) Magnesium and Magnesium Alloys. ASM International, p. 298.

Blažek D. (2012) Analysis of internal damping spectrum of magnesium alloys. Žilina: Žilinská Univerzita.

Blažek D. and Palček P. (2012) Measuring of internal friction by the resonance method. In: 29th International Colloquium, advanced manufacturing and pepair technologies in vehicle industry. Žilina Terchová.

Blažek D., Palček P., Trojanová Z., Porubčan J. (2001) Dependent Internal Friction of magnesium alloy AZ31 at room temperature. In: 16th International Conference on Internal Friction and Mechanical Spectroscopy, ICIFMS-16. Lausanne. Code 88192

Göken J., Swiostek J., Letzig D., Kainer K. U., (2005) Damping Measurements of the Magnesium Wrought Alloys AZ31, AZ61 and AZ80 After Indirect and Hydrostatic Extrusion. Mat. Sci. Forum, 482, pp. 387-390.

Horvath E., Torok A. and Harsanyi G., (2012a) Design and application of low temperature co-fired ceramic substrates for sensors in road vehicles. Transport, 27 (5), pp. 23-35.

DOI: $10.3846 / 16484142.2013 .782464$
Horvath E., Henap G., Torok A., Harsanyi G. (2012b) Mechanical characterization of glass-ceramics substrate with embedded microstructure. Journal Of Materials Science-Materials In Electronics, 23 (12), pp. 2123-2129. DOI: $10.1007 / \mathrm{S} 10854-012-0718-5$

Hovath E., Hénap G., Török Á., Harsányi G. (2012c) Mechanical Modelling And Life Cycle Optimisation Of Screen Printing. Journal Of Theoretical And Applied Mechanics, 50 (4), pp. 1025-1036.

Horvath E., Henap G. and Harsanyi G. (2012d) Finite element modeling of channel sag in LTCC. Microelectronics International, 29 (23), pp. 145-152. DOI: $\underline{10.1108 / 13565361211252908}$

Kasencak M. (2010) Vnútornétlmeniezliatinhorčika v závislostiodamplitúdydeformácie. Žilina: Žilinská Univerzita. p. 97.

Markovits T., Bauernhuber A. and Mikula P. (2013) Study on the transparency of polymer materials in case of $\mathrm{Nd}$ : YAG laser radiation. Periodica Polytechnica Transportation Engineering, 41 (2), pp. 149-154. DOI: $10.3311 /$ PPtr.7117 
Markovits T. and Bauernhuber A. (2014) Hybrid joining of steel and plastic materials by laser beam. Transport, 29 (2), pp. 217-222. DOI: $10.3846 / 16484142.2013 .785445$

Namesny A. (2008) Štúdiumvlastnostíhorčíkovýchzliatinmeranímvnútor néhotlmenia. Žilina: Žilinská Univerzita, p. 90.

Porubcan J. et al. (2012) Internal Friction in Extruded Aluminium Alloy. Solid State Phenomena, 184, pp. 197-202. DOI: 10.4028/www.scientific.net/SSP.184.197

Riehemann W. (1998) Internal Friction in Magnesium Materials. Magnesium Alloys and Their Applications. Frankfurt: Werkstoff-Informationsgesellschaft, p. 61.

Soviarová A., Palcek P. and Blazek D. (2013a) Analysis of Spurious Effects on Ultrasonic Internal Damping Testing Equipment. In: Transcom 2013 10th European Conference of Young Researches and Scientists, Žilina, pp. 197-182.
Soviarová A., Dresslerová Z., Palček P., Blažek D. (2013b) Influence of the precipitation and plastic deformation on the hardness of $A Z 61$ alloy. In: 27th Danubia-Adria symposium on advances in experimental mechanics. Primošten.

Sugimoto K. (1975) Effect of Crystal Orientation on Amplitude-Dependent Damping in Magnesium. Trans JIM, 16, pp. 647-655.

Weltsch Z., Fogarassy Zs., Lovas A., Takács J., Cziraki A., Tichy G. (2013) The Contact Angle Between Ag-Based Melts and Graphite Substrate and the Texture Evolution During the Subsequent Solidification. Acta Electrotechnica Et Informatica, 13(1), pp. 41-44. DOI: $\underline{10.2478 / \text { aeei-2013-0008 }}$ 